\title{
Molecular profiling of an oleaginous trebouxiophycean alga Parachlorella kessleri subjected to nutrient deprivation for enhanced biofuel production
}

\author{
Kashif Mohd Shaikh ${ }^{1,2}$, Asha Arumugam Nesamma ${ }^{1}$ Malik Zainul Abdin² and Pannaga Pavan Jutur ${ }^{*}$ (1)
}

\begin{abstract}
Background: Decreasing fossil fuels and its impact on global warming have led to an increasing demand for its replacement by sustainable renewable biofuels. Microalgae may offer a potential feedstock for renewable biofuels capable of converting atmospheric $\mathrm{CO}_{2}$ to substantial biomass and valuable biofuels, which is of great importance for the food and energy industries. Parachlorella kessleri, a marine unicellular green alga belonging to class Trebouxiophyceae, accumulates large amount of lipids under nutrient-deprived conditions. The present study aims to understand the metabolic imprints in order to elucidate the physiological mechanisms of lipid accumulations in this microalga under nutrient deprivation.
\end{abstract}

Results: Molecular profiles were obtained using gas chromatography-mass spectrometry (GC-MS) of P. kessleri subjected to nutrient deprivation. Relative quantities of more than 60 metabolites were systematically compared in all the three starvation conditions. Our results demonstrate that in lipid metabolism, the quantities of neutral lipids increased significantly followed by the decrease in other metabolites involved in photosynthesis, and nitrogen assimilation. Nitrogen starvation seems to trigger the triacylglycerol (TAG) accumulation rapidly, while the microalga seems to tolerate phosphorous limitation, hence increasing both biomass and lipid content. The metabolomic and lipidomic profiles have identified a few common metabolites such as citric acid and 2-ketoglutaric acid which play significant role in diverting flux towards acetyl-CoA leading to accumulation of neutral lipids, whereas other molecules such as trehalose involve in cell growth regulation, when subjected to nutrient deprivation.

Conclusions: Understanding the entire system through qualitative (untargeted) metabolome approach in P. kessleri has led to identification of relevant metabolites involved in the biosynthesis and degradation of precursor molecules that may have potential for biofuel production, aiming towards the vision of tomorrow's bioenergy needs.

Keywords: Microalgae, Biofuels, Metabolomics, Parachlorella kessleri, Nutrient deprivation

\section{Background}

The global energy demand is increasing day by day as the energy consumption is rising and is expected to increase by $53 \%$ within the next two decades. The fossil-derived

\footnotetext{
*Correspondence: jppavan@icgeb.res.in

${ }^{1}$ Omics of Algae Group, Integrative Biology, International Centre for Genetic Engineering and Biotechnology, Aruna Asaf Ali Marg, New Delhi 110067, India

Full list of author information is available at the end of the article
}

diesel has been an important source of transportation fuel, but a significant need has come up to look for alternate sources of energy as the conventional source is non-regenerable and costs a lot to the environmental sustainability. The fossil fuel reserves are limited, and as their sources perish, the world will face a huge hike in fuel prices. Since the food and fuel prices are interdependent, the increase in fuel prices will ultimately influence the cost of food [1]. The rapid increase in energy consumption globally has raised the requirement for the 
development of sustainable renewable energy sources. In the need of current scenario, the production of biodiesel has increased considerably in the recent past with annual production reaching over billions of litres. Mostly waste cooking oil, soybean oil, palm oil, etc. have been used for the production of biodiesel. However, this conventional mode of production, perhaps in the near future, will lead to competition for land usage in terms of fuel and food. Hence, microalgae are being looked upon as a potential source for biodiesel production and have gained considerable attention because of their capability to utilize sunlight and water to convert atmospheric $\mathrm{CO}_{2}$ into biomass and biofuels which can prove to be important for both food and energy requirements $[2,3]$.

Microalgae can produce biomass along with the accumulation of large quantities of lipids/triacylglycerols (TAGs) for biodiesel production. The major advantage for the production of biodiesel from microalgae is their ability to produce large amount of biomass and lipid photosynthetically, and their ability to grow on non-arable land using saline and/or waste waters that make them free from any competition with resources required for growing food [4-7]. Other advantages include their capability to sequester greenhouse gas, a major environmental benefit as the world is facing huge climatic change manifested with conventional fuel utilization $[8,9]$; their ability to absorb nutrients from waste waters helping in bioremediation, which is both economical and environment friendly [10, 11]; and their ability to synthesize certain high-value co-products such as OMEGAs, astaxanthin, lutein, tocopherols that are essential for industrial production in pharmaceuticals, nutraceuticals, etc. $[12,13]$. One important lead with microalgal-TAG-based biodiesel-derived fuels is their easy integration into the current infrastructure of transportation fuels [14]. Some microalgae can produce TAGs when grown under heterotrophic mode [15], and under autotrophic mode of growth, numerous factors tend to stimulate lipid production such as nutrient availability, light, temperature [16, 17]. Even through microalgae hold potential feedstock for the production of lipids, the accumulation of oil tends to amplify under stress conditions but perhaps the major concern is inhibition of growth, thus simultaneously hampering biomass [18].

Despite such a huge potential microalgae hold for a sustainable source of renewable energy, a number of challenges exist in way for their commercialization as biofuel source. Few microalgal species have been identified as a promising source for industrial-level biofuel, nutraceuticals and pharmaceutical productions, but various research efforts are still being carried out to make microalgal biofuels cost-effective and sustainable. The diverse genera of algae lead to their exceptionally wide range of lipid and metabolic profile which is a result of their dynamic environmental condition [19]. Hence, detailed study on selection, culturing condition optimization, large-scale bioreactor development, bioengineering for better biomass and biofuel, improvement in biomass harvesting and other downstream processing is being carried out to reduce the production cost [20-23]. Several attempts have been made to improve strain performance, harvesting, extraction and culture systems to bring down the economic input for large-scale production [24-28]. The lipid composition among microalgae varies between 10 and $60 \%(\mathrm{dw})$ because of the wide range of strains as well as the environmental conditions in which they occur and/or are cultivated $[29,30]$. The primary requirement for industrial production of microalgae-based biodiesel is the screening for conditions that induce high lipid productivity in fast-growing microalgae that can fulfil the criteria for sustainable biofuels. Henceforth, in-depth understanding of such phenomenon might also provide deeper insights into the bioengineering of industrially feasible strains. A number of biochemical strategies have been used in this direction to enhance lipid and biomass production [31, 32]. Various environmental factors affect the microalgal cultivation, altering its biomass and biochemical composition [33, 34]. Menon et al. [16] showed that generation of specific intracellular reactive oxygen species (siROS) during stress acts as a common signal that affects various metabolic pathways including lipid biosynthesis. The availability of nutrients affects the microalgal growth as well as their lipid and metabolic compositions [35, 36]. Hence, limiting nutrient availability in the media to induce metabolic variations and lipid accumulation in microalgae is an important alternative strategy to understand the initiation and storage of TAGs in the system.

Despite the significance of various metabolic products in regulating the cellular dynamics, and mechanisms that control the partitioning of these metabolites into distinct carbon-storing molecules in algae, their role in algal physiology and biofuel precursors production is poorly illustrated. In the present work, we have focused on understanding the phenomenon of nutrient deprivation as a tool to enhance lipid productivity as well as the associated changes in the metabolic profiles and biochemical composition of indigenous marine microalga Parachlorella kessleri (I) under three different nutrient limitations, viz. nitrogen, phosphorous and sulphur. Previous studies on P. kessleri revealed its potential as a suitable candidate for biofuel production, with lipid content around $40-60 \%$ of dry cell weight [37-40]. The significance of selecting this indigenous marine microalgae $P$. kessleri (I) is mainly due to its better biomass productivity and higher lipid content as reported earlier 
$[37,40]$. Our rationale highlights up on building a crosstalk between the metabolomic changes and cellular dynamics in terms of biomass and lipid productivities, when this marine microalgae is subjected to nutrient deprivation.

\section{Results}

\section{Growth and biochemical analysis}

The primary impact of nutrient stress is visible on the growth pattern, so the biomass accumulation was analysed for $P$. kessleri under the nitrogen-, phosphorousand sulphur-deprived conditions. The growth parameters of the marine strain P. kessleri under standard growth conditions with an initial inoculum of $\sim 0.057 \mathrm{~g} \mathrm{~L}^{-1}$ produced a biomass of $0.54 \mathrm{~g} \mathrm{~L}^{-1}$ in 10 days, thus exhibiting better growth rate, achieving specific growth rate of $0.67 \mu$ and doubling time around $24.7 \mathrm{~h}$. Several studies have shown that microalgae growth depends on an adequate supply of essential macronutrient elements (carbon, nitrogen, phosphorus, silicon), major ions $\left(\mathrm{Mg}^{2+}\right.$, $\left.\mathrm{Ca}^{2+}, \mathrm{Cl}^{-}, \mathrm{So}_{4}^{2-}\right)$ as well as on a number of micronutrient metals such as iron, manganese, zinc, cobalt, copper and molybdenum [41]. To analyse the effect of different nutrient depletions such as nitrogen $(\mathrm{N}-)$, phosphorus (P-) or sulphur (S-) on the growth profile, P. kessleri was grown under continuous photoautotrophic conditions. The results demonstrated that this strain had severe effect on growth in nitrogen $(\mathrm{N}$-) deprivation, i.e. growth was shunted within 4 days of deprivation after which no change in biomass was observed (Fig. 1a). In sulphur (S-) deprivation and phosphorous (P-) deprivation, no significant change in growth rate was observed till the sixth day (Fig. 1a). In P. kessleri, the effect of sulphur (S-) depletion on growth was delayed as compared to nitrogen deprivation. Inset (Fig. 1a) demonstrates the cultures in different deprivation conditions which show growth retardation as well as loss in pigmentation (indicated by pale green colour). The nitrogen concentration in the same medium deficit in $\mathrm{N}$-, $\mathrm{P}$ - and $\mathrm{S}$ - during the microalgae culture was also estimated. In P- and S- conditions, the nitrogen utilization was slower when compared to the control. Most of the nitrogen was utilized by microalgae at the end of the sixth day in the control, whereas in P- and S- conditions it was completely consumed by the end of the tenth day. This pattern is also observed in the growth profile as the

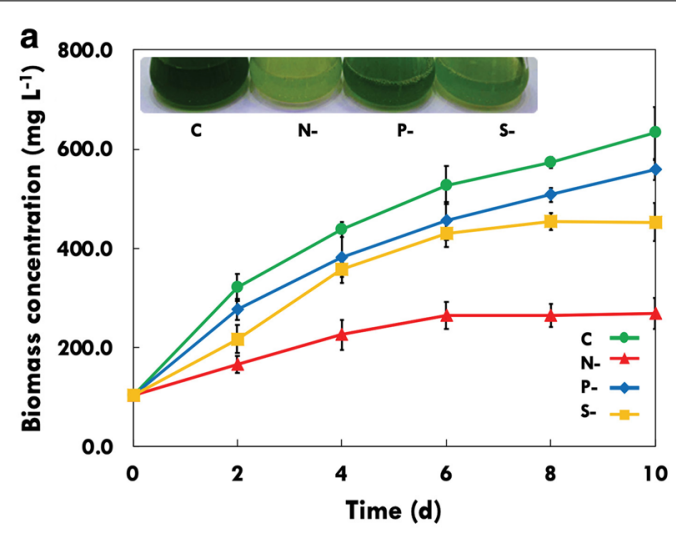

b
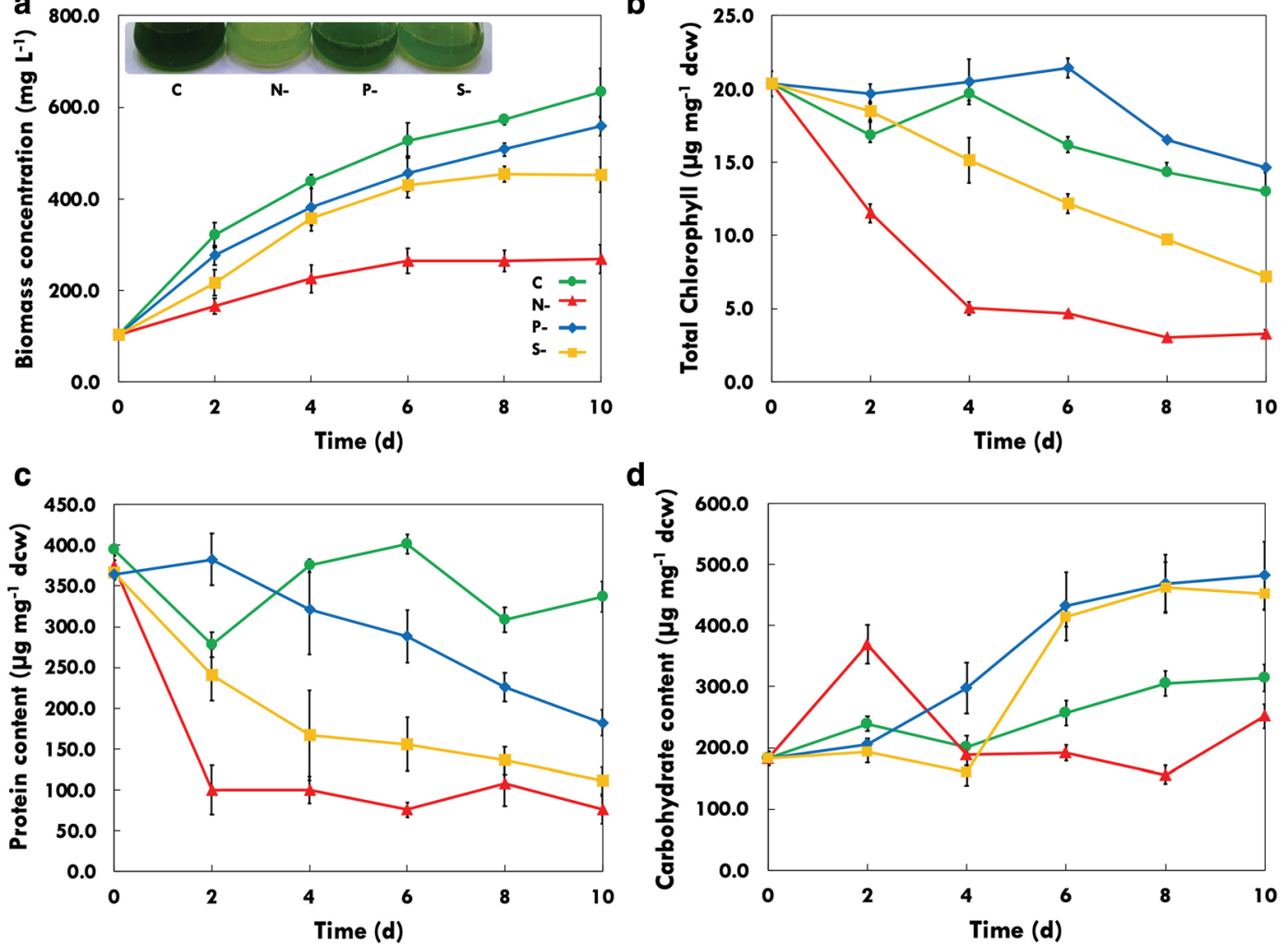

d

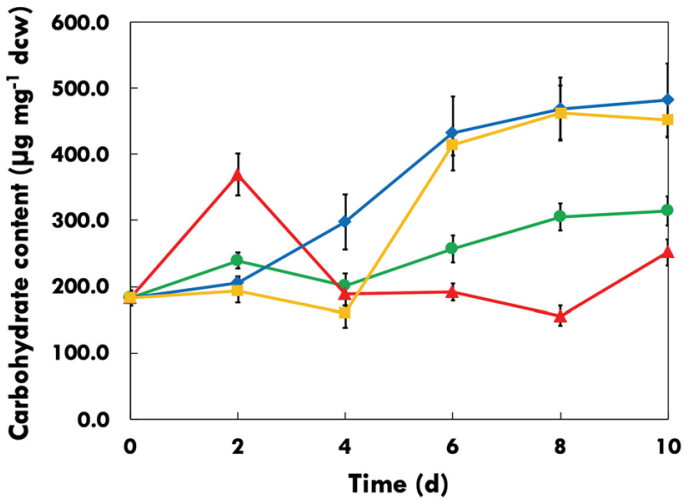

Fig. 1 Biochemical profiles of Parachlorella kessleri under control and stress conditions. a Growth profiles, $\mathbf{b}$ total chlorophyll, $\mathbf{c}$ protein and $\mathbf{d}$ carbohydrate contents; $\mathrm{C}$, control; $\mathrm{N}$-, nitrogen deprivation; $\mathrm{P}-$-, phosphorous deprivation; $\mathrm{S}$-, sulphur deprivation; days of treatment-0, 2, 4, 6, 8 and 10 days 
cell growth slows down and shifts towards stationary phase.

Various biochemical constituents were analysed to understand the effect of nutrient starvation over molecular profiling in $P$. kessleri. Figure $1 \mathrm{~b}-\mathrm{d}$ shows the pigment (total chlorophyll), protein and carbohydrate profiles subjected to different nutrient deprivation conditions. The total chlorophyll content was severely reduced under $\mathrm{N}$ - stress, while S- deprivation leads to a steady loss of pigments over time. Phosphorus (P-) deprived cells maintained their net chlorophyll levels up to 4-6 days followed by decline in prolonged stress (Fig. 1b). During $\mathrm{N}$ - stress, the chlorophyll content was severely deteriorated within 2-4 days of starvation, while P- and S- cells showed a slow decrease. Photosynthetic machinery is the primary component to be affected by severe nutrient deprivation, especially in case of nitrogen deprivation as reported in most of the microalgal strains [42].

The total protein content was also decreased rapidly in case of nitrogen-deprived cells and reached the minimum by the end of the second day. In case of S- deprivation, the decrease was steady over time, whereas in $\mathrm{P}$ - stress the protein content started declining after the fourth day (Fig. 1c). During P- and S-conditions, the protein content in the cells declined slowly, but the initial impact on protein machinery was not adverse as seen during $\mathrm{N}$ - starvation. When algae are subjected to nutrient deprivation, the cells start to reduce the protein build up and catabolize proteins to use the carbon skeleton to synthesize storage molecules. Figure 1d demonstrates the changes occurring during nutrient stress in the carbohydrate content. Under $\mathrm{N}$ - deprived cells, an initial rise in the total carbohydrate content was observed on day 2 ( onefold), after which it has declined rapidly (Fig. 1d). Our presumption predicts that $P$. kessleri isolated from marine waters may certainly not be a predominant carbohydrate producing strain. Under P- and S- deprivation, an increase in the carbohydrate content was observed till the fourth day. Increase in carbohydrate as a storage molecule has been observed in many algal species, mainly fresh water species, when the cells are subjected to nutrient deprivation.

\section{Lipid analysis and profiling}

Lipid accumulation in algae is induced normally due to environmental stress, particularly when deprived of certain nutrients such as nitrogen, phosphorus, silica, sulphur or certain metals [43, 44]. In microalgae, nutrient deprivation to enhance the production of lipids is a wellobserved phenomenon [33, 45]. During stress-induced lipid accumulation, the lack of essential nutrients such as $\mathrm{N}, \mathrm{P}$ and $\mathrm{S}$ restricts the capacity of cellular division as a result of which the organism shifts towards alternative pathways for inorganic carbon assimilation, thus shuffling the carbon towards the storage biomolecules, i.e. TAGs. To demonstrate the effect of different nutrient deprivation on the synthesis of TAGs, total lipid was extracted from cells and analysed using thin-layer chromatography (TLC) as described in "Methods". The TLC plate loaded with extracted lipids from samples of the three stress conditions (N-, P- and S-) led to a sharp increase in the TAG content in P. kessleri, where TAG seems to increase with the progression of duration of starvation (data not shown). Further, the samples were quantified using GC-MS analysis to evaluate the lipid productivity subjected to nutrient stress. Sulphur (S-) depletion induced TAG formation to a much lesser extent as compared to other nutrient-deprived conditions. The increase in TAG content can be observed from the second day itself in $\mathrm{N}$ - condition, whereas in P- and S- depletion TAG accumulation was observed after the fourth day (Fig. 2a). In P- depletion, a gradual increase in TAG content was observed without compromising cell growth. Under Nstress, the TAG production has been initiated on day 2 itself and reached maximum by the tenth day, but also lead to severe growth inhibition depicting metabolic changes within the cells. In marine microalgae P. kessleri, S- depletion lead to inhibition in growth after day 6 but in comparison with $\mathrm{N}$ - and $\mathrm{P}-$, the increase in lipid content was not very significant (Fig. 2a).

A number of changes occur in the overall neutral lipid content as well as the saturation profile of lipids when microalgae are subjected to nutrient deprivation [46]. Figure 2a, b shows the lipid content $\left(\mu \mathrm{g} \mathrm{mg}^{-1} \mathrm{dw}\right)$ and FAME productivity $\left(\mathrm{mg} \mathrm{L}^{-1}\right.$ day $\left.^{-1}\right)$ analysed through GC/MS under different nutrient $(\mathrm{N}$, $\mathrm{P}$ and S) deprivation conditions compared to the control in P. kessleri. Our data show that FAME productivities were similar in $\mathrm{N}-\left(\sim 11.63 \mathrm{mg} \mathrm{L}^{-1}\right.$ day $\left.^{-1}\right)$ and P- $\left(\sim 11.58 \mathrm{mg} \mathrm{L}^{-1} \mathrm{day}^{-1}\right)$, while lower in case of S- deprivation $\left(\sim 7.13 \mathrm{mg} \mathrm{L}^{-1} \mathrm{day}^{-1}\right)$ at the end of the sixth day (Fig. 2a). As compared to nitrogen and phosphorous depletion, the FAME productivity under sulphur limitation was substantially low (Fig. 2a).

The FAME content per cell seems to be higher in Nstress (Fig. 2a), where a constant increase in lipid accumulation was observed, i.e. reaching up to $>40 \%$ of dry cell weight, while in P- the lipid content per cell remains low as compared to $\mathrm{N}$ - cells but is considerably higher than control (Fig. 2a inset). Overall, the time-dependent changes in lipid content for 10 days in different stress conditions are shown in Fig. 2a (inset). In the present study, P. kessleri subjected to $\mathrm{N}$ - has shown enhanced neutral lipid content, whereas $\mathrm{P}$ - tends to have a steady increase (Fig. 2a). 

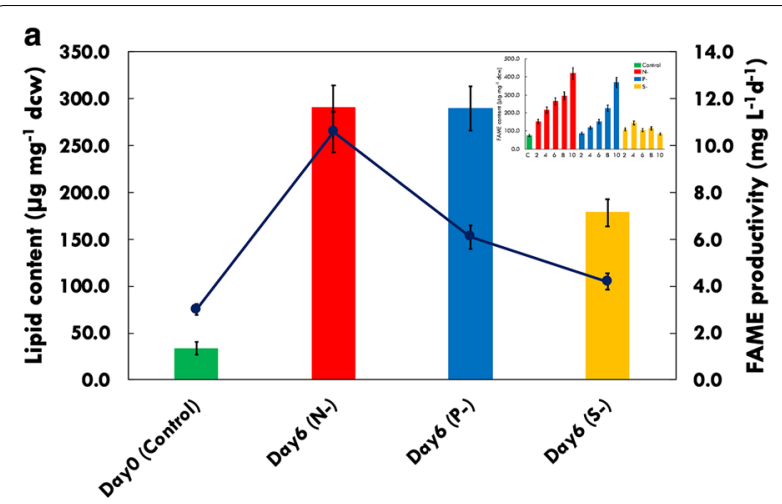

b

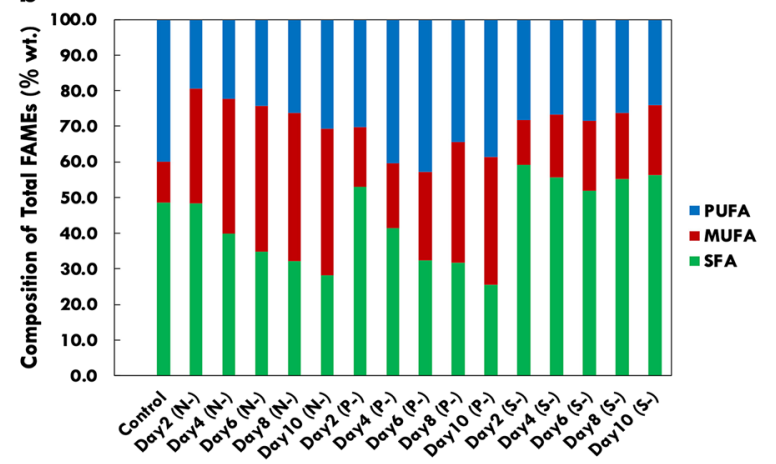

Fig. 2 a Total lipid content (represented as line graphs) and FAME productivity (in bars) under control and nutrient-deprived conditions for day 6 . Inset shows the change in FAME content with stress conditions, days of treatment-0 (control), 2, 4, 6, 8 and 10 days. b Changes in saturated (SFA), monounsaturated (MUFA) and polyunsaturated (PUFA) profiles of fatty acids under nutrient-deprived conditions; $\mathrm{N}$-, nitrogen deprivation; $\mathrm{P}-$, phosphorous deprivation; S-, sulphur deprivation; days of treatment-0 (control), 2, 4, 6, 8 and 10 days

On initial day (control) of inoculation, FAME profiling patterns showed highest content of polyunsaturated fatty acids (PUFAs) and saturated fatty acids (SFAs) than monounsaturated fatty acids (MUFAs) (Fig. 2b). Under N- conditions, $P$. kessleri exhibits an increase in MUFAs (up to $41 \%$ of total FAME) with considerable decrease in SFAs (to 35\%) and PUFAs (to $\sim 24 \%$ ) by the end of the tenth day. This can be a result of the oxidative damage to PUFAs under stress [47] or recycling of membrane lipids towards TAGs [48]. Although P- limitation induced lipid biosynthesis, at the end of deprivation period, the FAME pattern suggests decrease in SFAs (to 32.5\%) and considerable increase in MUFAs (to $\sim 24.5 \%$ ) and PUFAs (to 43\%). In S- depleted cells, SFAs increased (to $\sim 52 \%$ ) with a little upregulation in MUFAs (to 20\%) while PUFAs decreased (Fig. 2b).

\section{Metabolome analysis}

Metabolite levels are tightly controlled during the starvation condition to enhance the chances of survival. A

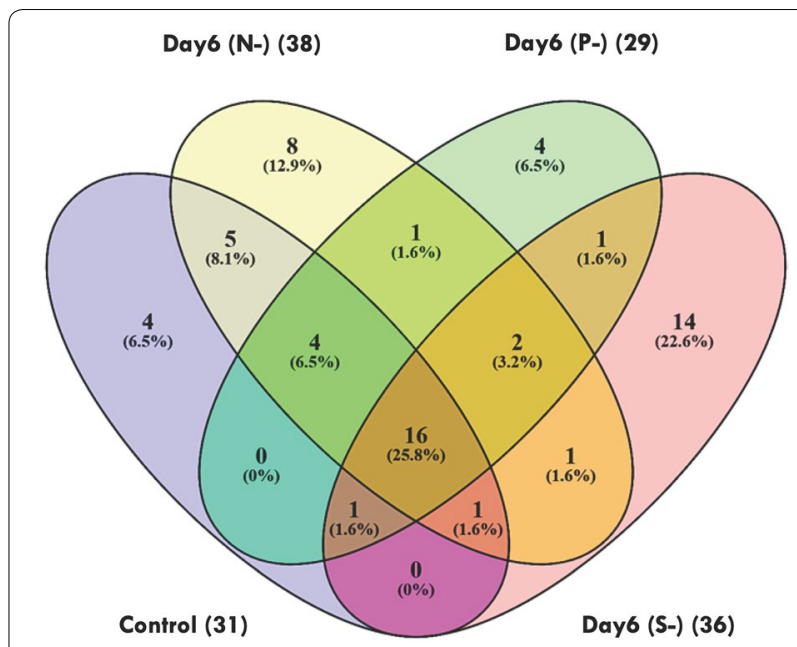

Fig. 3 Venn diagram representing various metabolites in different stress conditions. C, control; N-, nitrogen deprivation; P-, phosphorous deprivation, S-, sulphur deprivation. Numbers in brackets show total metabolites obtained in each condition

number of changes were observed in terms of growth and biochemical profiles under different nutrient starvation conditions. Therefore, to understand the molecular profiling, we have employed qualitative metabolomics tool to evaluate the changes occurring during stress which will provide new insights for enhancing the lipid production. The metabolite extraction and derivatization were carried out in all the samples of $P$. kessleri as described in "Methods" section. A total number of $\sim 62$ metabolite peaks were obtained after manual curation and analysis of raw data. The most common phenomenon observed in the raw data files is the repetition of same metabolite as a result of alternate derivatization [36]; such metabolites were removed if not significant. All the metabolites analysed in P. kessleri under different nutrient deprivation were plotted using Venny 2.1 (http://bioinfogp.cnb.csic. es/tools/venny/) to find out intersecting and differential metabolites (Fig. 3). Among these, eight metabolites were exclusively expressed under $\mathrm{N}$-, four in $\mathrm{P}$ - and 14 in Sconditions (Fig. 3).

Certain metabolites were common in all stress conditions, while certain were common in two conditions, as discussed later. The fold change for all the metabolites subjected to stress conditions either upregulated or downregulated as compared to the control is shown in Fig. 4a-c. (The list for metabolites with their representative numeric code is included.) In $\mathrm{N}$ - cells, many metabolites such as valine, trehalose, citric acid, mannose, linoleic acid, trans-9-octadecanoic acid, talose were found to increase > twofold, while malic acid, myo-inositol, glucose, polyunsaturated fats were predominantly decreased (Fig. 4a). In P- cells, upregulated metabolites 
include citric acid, galactose, mannose, threose, while myo-inositol, glucose, azelaic acid, sorbose, a-tocopherol were decreased (Fig. 4b). In S- cells, metabolites such as trehalose, mannitol, galactose, mannose were increased, while malic acid, glutamic acid, citric acid, myo-inositol decreased (Fig. 4c).

The overall metabolomic profiles in P. kessleri when subjected to nutrient deprivation have been illustrated as a heat map for the visualization of expression profiles of various metabolites (Fig. 5).

An essential metabolite of interest, citric acid, was found to be upregulated nearly by fivefold in only $\mathrm{N}$ - and $\mathrm{P}$ - conditions. It seems to be an important metabolite in upregulating the FA biosynthesis as it increased in both $\mathrm{N}$ - and $\mathrm{P}$ - conditions where lipid accumulation has also increased, while it decreased in S- where lipid accumulation is much lower as compared to other two conditions. Also, 2-ketoglutaric acid was found to increase in the similar conditions by twofold, both together assume to divert flux towards FA biosynthesis [49]. Another metabolite of importance is trehalose that was found enhanced fivefold in $\mathrm{N}$ - and S- but not in P-conditions that may presumably play a significant role in cell growth regulation. Significant metabolite changes occur when subjected to nutrient depletion (N-, P- and S-) conditions, and each of these changes will affect cell growth and lipid productivities. Henceforth, our metabolomic data provide us with the schematic model to understand flux diversion that leads to changes in lipid productivity and growth rate under different nutrient stresses (Fig. 6).

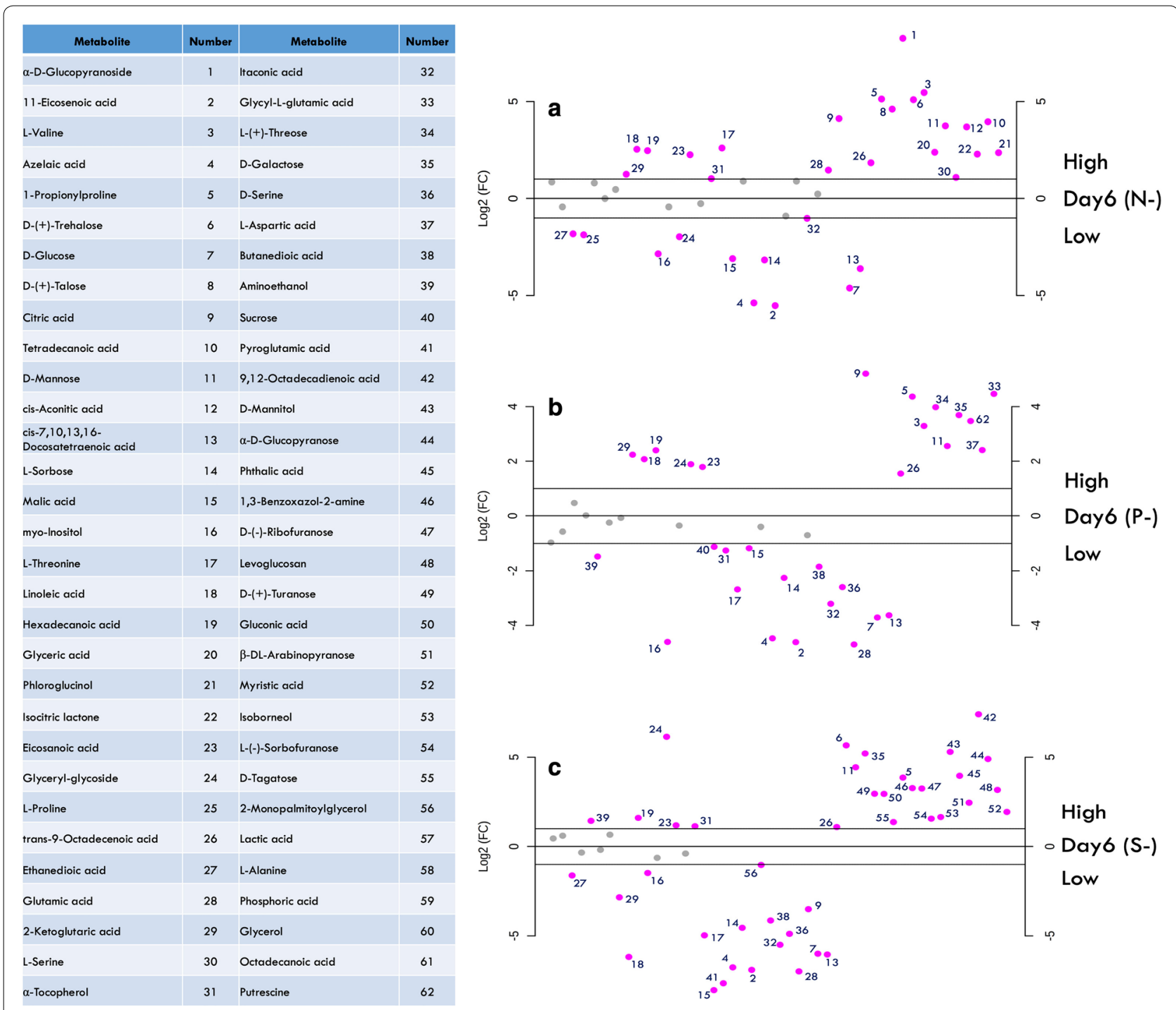

Fig. 4 Fold-change in metabolites under stress conditions; a nitrogen deprivation: N-, b phosphorous deprivation: P-, c sulphur deprivation; table represents numerical abbreviations of the metabolites 


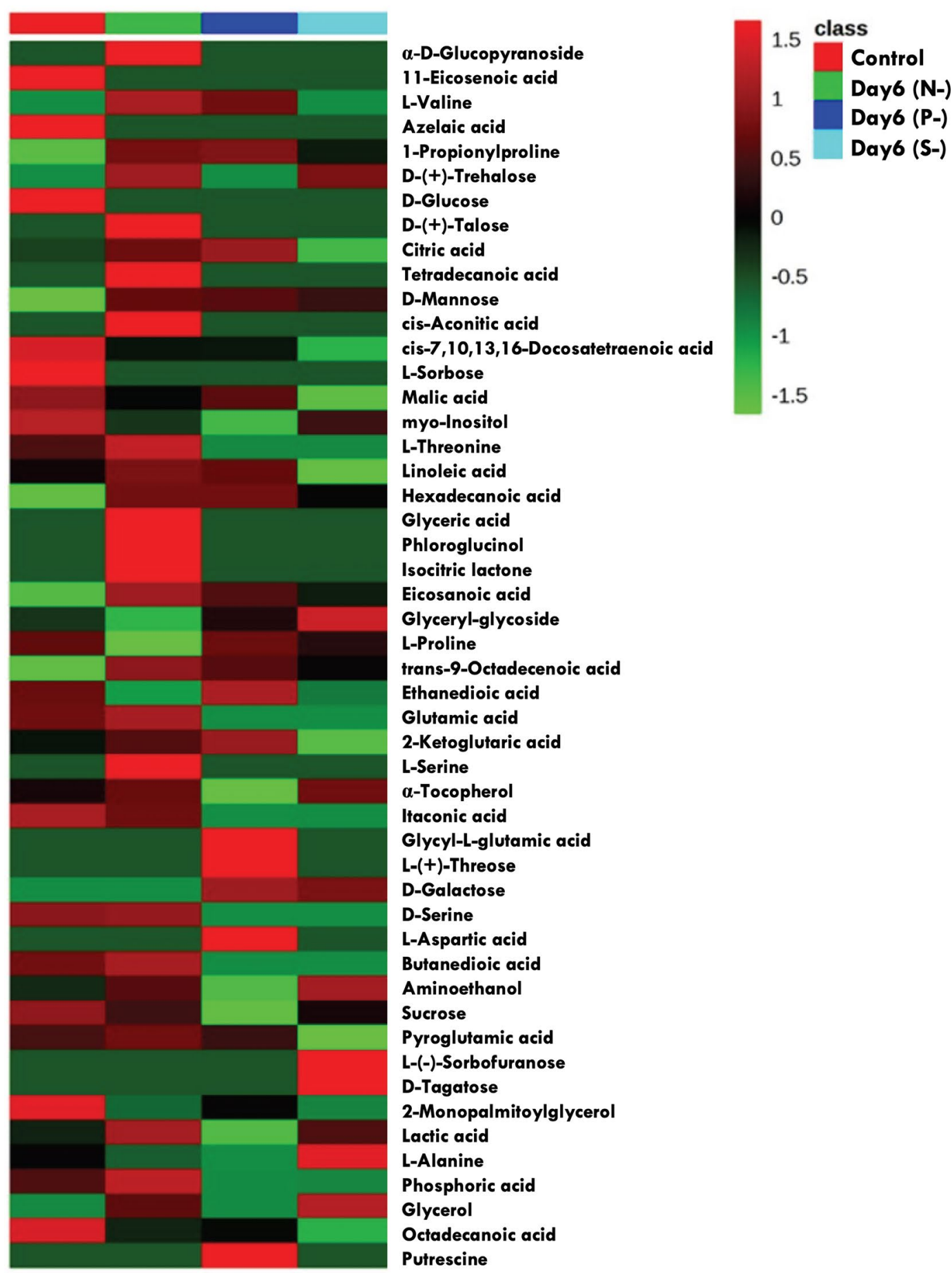

Fig. 5 A heat map illustrating the expression of all the metabolites under nutrient deprivation conditions. $\mathrm{N}-$, nitrogen deprivation; $\mathrm{P}-$, phosphorous deprivation; S-, sulphur deprivation

\section{Discussion}

Growing bioenergy needs demand urgent action to generate renewable fuels at feasible cost. Algae seem to be a promising bioresource in terms of economically feasible bioenergy producer, yet the information regarding cellular dynamics of microalgal cells is fairly poor. The primary focus in algal research has been the enhancement of lipid production employing nutrient stress while 
biomass productivities are essentially compromised. A number of strategies, such as nutrient deprivation, light intensity, temperature variation, carbon dioxide have been employed to reach specific goals, but the cellular behaviour under these conditions is yet not well established. Under the adequate supply of nutrients including C, N, P, S and light, depending on the strain selection, the biomass productivity can be high but the lipid content seems to be as low as 5\% w/w or even less [50]. During unfavourable conditions, the microalgal growth and photosynthetic activity cease, while the excess energy gets assimilated as lipids and/or carbohydrates. Metabolically, there is always a competition between biomass and storage molecule assimilation, which governs and channelizes the carbon flux either towards biomass accumulation or towards lipid and carbohydrate synthesis. Depending on the requirement, a metabolic shift can switch the photosynthetic assimilation of inorganic carbon from biomass synthesis to energy storage metabolism [51, 52]. Changes in the environmental conditions such as light intensity, nutrient limitation, salinity, temperature, $\mathrm{pH}$, and culture age invariably affect the lipid content of microalgae [5359]. Oleaginous microalgae can utilize their lipid metabolic pathway for the biosynthesis and accumulation of lipids in the form of triacylglycerols (TAGs) [60]. Some of these oleaginous microalgae can even store TAGs up to $40 \%$ to $70 \%$ of their dry weight $[33,61]$. These lipids are typically storage reserves within the cell that helps the organism to sustain adverse environmental conditions. Henceforth, the competition in terms of biomass (or) lipid accumulation depends upon the different levels of perturbation [62]. In the present work, growth and cellular physiology of $P$. kessleri were demonstrated under different nutrient deprivations. While growth was severely hampered under $\mathrm{N}$ - deprivation, the cells were able to withstand phosphorus or sulphur absence fairly well, although after 6 days the $S$ - cells showed high decline in growth. Perhaps the nutrient deprivation can be attributed to the evolutionary behaviour of microalgae, for example in marine waters the phosphorous availability is quite dynamic, and hence, these photosynthetic organisms do have specialized responses to maintain their

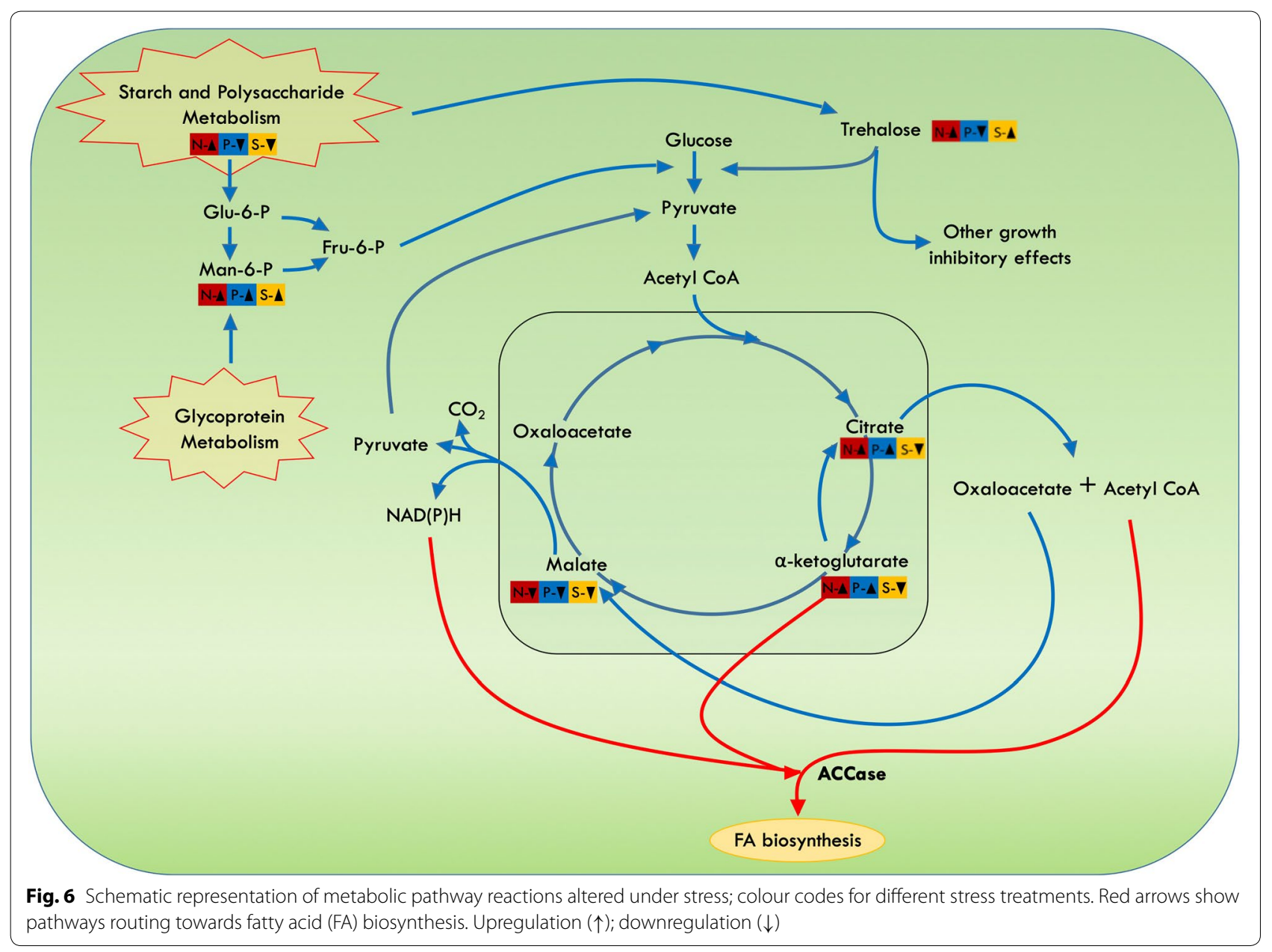


growth under certain nutrient depletion conditions [63, 64]. Nitrogen, a major component of proteins, enzymes and nucleotides, is extremely essential, without which growth cannot be sustained.

A number of physiological changes are observed when microalgae are subjected to nutrient deprivation. During stress, the cell machinery will try to minimize the protein synthesis due to non-availability of nitrogen by shutting down the protein biosynthesis and degrading the protein pool to amino acids to get energy for survival as well as to assimilate carbon as storage molecules. Under nutrient-deprived condition, the total chlorophyll content decreased as the days of starvation progressed. Under nitrogen-deprived condition, the chlorophyll content was severely deteriorated within 2 to 4 days of starvation, while phosphorous- and sulphur-starved cells showed a slow decrease. Chlorophyll reduced to almost half within 2 days of nitrogen starvation (Fig. 1b). This is a very common phenomenon observed under nitrogen stress among other strains too. The protein content did show variable response to different stress conditions. Under nitrogen deprivation, rapid lowering in protein content is observed. The cell machinery tries to cope up with nitrogen unavailability by cutting down on protein synthesis and degrading the protein pool to amino acids to get energy for survival as well as to divert carbon towards storage molecules. Phosphorous- and sulphurstarved cells also showed a slow decline in the protein content, but the initial impact on protein machinery was not as severe as nitrogen starvation Fig. 1c). A sharp increase in carbohydrates in nitrogen-starved cells was observed on the second day, where the carbohydrate content was doubled, which later decreased substantially. This initial response might be attributed to the formation of carbohydrates as energy storage molecule in the case of extreme nitrogen limitation, which later provides carbon skeleton for lipid biosynthesis as storage molecules under prolonged starvation. The increase in carbohydrate content in phosphorous- and sulphur-starved cells was observed after day 4 , and the lipid accumulation was observed late as compared to nitrogen-starved cells (Figs. 1c, 2a). These observations suggest that the microalgae initially store carbohydrates energy reserves to overcome the initial stress and then utilize the same for energy generation when they are subjected to severe macronutrient limitation. This has been reported in various microalgae, where some accumulate starch under nutrient depletion condition, others accumulate lipids, or an initial starch accumulation followed by lipid accumulation over prolonged stress is observed [65-69]. In conclusion, adverse effects in molecular profiles of biomolecules (such as total chlorophyll, proteins and carbohydrates) were seen during $\mathrm{N}$ - and $\mathrm{S}$ - conditions with hampered cell growth (biomass), whereas P- stress seems to have a limited effect.

Under optimal conditions, photosynthesis and electron transport chain produce ATP and NADPH which is utilized as energy currency during cell division [70]. Hence, the optimal ratio of reduced and oxidized metabolites is maintained, whereas during nutrient deprivation the pool of NADP+ and ADP depletes as photosynthesis continuously produces NADPH and ATP which remains under-utilized [62]. Biosynthesis of fatty acid consumes NADPH and ATP; hence, the increased fatty acid synthesis helps the cells to maintain the balance of required electron acceptors (NADP+). During nutrient limitation, an increase in the lipid content has been demonstrated in several microalgal species $[38,63,71]$. Nitrogen is an essential requirement for protein synthesis as well as photosynthesis, but under nitrogen-limiting conditions most of the carbon fixed in photosynthesis is channelized towards the production of lipids and/or carbohydrates. Several studies have demonstrated that nitrogen deprivation leads to higher accumulation of lipids in various microalgal strains $[72,73]$. Upon removal of nitrogen, Nannochloropsis sp. and Neochloris oleoabundans increased their lipid content to onefold and twofold, respectively [74, 75]. A number of cellular metabolic processes such as photosynthesis, signal transduction, energy transport system require phosphorous as the main component, and hence, the deficiency of this major element also results in accumulation of lipids [76-78]. Similar studies showed increase in lipid accumulation to more than $50 \%$ of dry weight $(\mathrm{dw})$ under P- limitation in Scenedesmus sp. LX1 belonging to Scenedesmaceae [79, 80]. In our present investigation, FAME content in $P$. kessleri was highest in N-cells, whereas in P-cells the same has been compensated by the better growth rate. This observation was unique as the cells were able to produce lipids without compromising growth and the mechanism is still to be exploited. Further investigation can provide us with novel insights for enhancement of lipids among specific strains without negotiating growth. However, the FAME profiling depicting the saturation and unsaturation levels was more promising in the case of $\mathrm{N}$ - cells. Nitrogen-deprived cells had a high level of SFAs and MUFAs, while PUFAs levels are decreased (Fig. 2b). This profile is more suitable in terms of biodiesel as the amount of polyunsaturation affects overall properties of biodiesel. Lower PUFA level is mainly helpful in lowering ignition delay, increasing stability against oxidation and lowering $\mathrm{NOx}$ emission [81], whereas in P- cells the PUFA content was higher than SFAs and MUFAs in P. kessleri.

A number of studies on Chlamydomonas have shown a strict metabolite regulatory network balancing the cellular processes under stress [82-84]. Various 
chromatographic techniques are used for the identification and analysis of metabolites from biological samples. Gas chromatography combined with mass spectroscopy (GC-MS) has become a popular technique to analyse metabolomic phenotypes, where GC separates the volatile compounds depending on their mass and polarity, while MS enables reproducible analyte fragmentation and identification $[85,86]$. The metabolomic analysis of the cells subjected to nutrient starvation has shown a number of metabolites, which had low match scores and/or duplicated because of the varying degree of sialylation. A total number of 62 metabolites were screened and analysed on the basis of their relative peak areas from deprived conditions. Since different conditions gave different metabolic profiles, we tried to explore those that can give a probable crosstalk among the various stresses. Overall, the downregulated metabolites were more or less common among all conditions, such as malic acid, sorbose, glucose, myoinositol (Figs. 4, 5). Also, sugar molecules obtained from polysaccharide degradation usually increased in starved cells, indicating a cut down of stored carbohydrates to provide carbon skeleton for lipid synthesis. In all stress conditions, two metabolites, i.e. 1-propionyl proline and mannose, were found to be upregulated compared to the control. Martel [87] reported increase in mannose, a C-2 epimer of glucose, which can be derived from the digestion of polysaccharides and glycoproteins under the nitrogen-deprived condition in Isochrysis galbana. However, in the present study increase in mannose seems to be higher in the $\mathrm{N}$ - condition due to cumulative breakdown of polysaccharides and glycoproteins, whereas in $\mathrm{P}$ - and S- stresses it may be due to glycoprotein metabolism alone. The predominant fatty acids depicted in the analysis are hexadecanoic acid, eicosanoic acid (arachidic acid) and trans-9 octadecanoic acid (elaidic acid) (Figs. 4, 5). Myo-inositol, a sugar alcohol, has also been reduced many folds under all the stress conditions. Inositol is an important component of structural lipids and may get disrupted during stress. In plants, the hexophosphate of inositol serves as a phosphate reserve [88] and the same mechanism may also be present in these microalgae as well because of the decreased content of myo-inositol in $\mathrm{P}$ - cells as compared to N- or S- cells. Henceforth, phosphate derivatives of myo-inositol might be broken down to provide phosphorous for cellular activities under Pdeprivation. Also, sorbose, another monosaccharide, and azelaic acid also seem to be utilized for cell survival in P. kessleri. Malic acid, an intermediate of tricarboxylic acid (TCA) cycle, is decreased during stress and predicts the downplay of the Calvin cycle. The decarboxylation of malate to pyruvate leads to the generation of $\mathrm{NAD}(\mathrm{P})$ $\mathrm{H}$, and both the pyruvate and $\mathrm{NAD}(\mathrm{P}) \mathrm{H}$ can be utilized for FA biosynthesis leading to lipid accumulation [89].
During $\mathrm{C}_{4}$ carbon fixation in plants, malate provides $\mathrm{CO}_{2}$ to Calvin cycle and such similar mechanism may co-exist in some marine diatoms and algae [90, 91]. In P. kessleri, the reduced photosynthetic machinery might also lead to the break down of malate as it will not be required to transport $\mathrm{CO}_{2}$. $\alpha$-Tocopherol was also enhanced in nitrogen and sulphur deprivation. $\alpha$-Tocopherol is another potent antioxidant that is enhanced under stress to protect cells from oxidative damage by quenching reactive oxygen [92] and also involved in the regulation of photosynthesis and macronutrient uptake and utilization [93].

Citric acid positively regulates acetyl-CoA-carboxylase which is the enzyme for the first committed step towards FA biosynthesis [94]. Citric acid is an intermediate of Calvin cycle; when transported from mitochondria to cytoplasm, it breaks down into oxaloacetic acid and acetyl-CoA diverting flux towards FA biosynthesis. Increased citrate may act as an acetyl-CoA carrier for fatty acid synthesis [95]. In Nannochloropsis salina, kinetic profiles and activity studies showed that this Eustigmatophyceae strain is able to convert sugar via citrate cycle towards lipids [96] and the exogenous supply of citrate showed increased fatty acid biosynthesis in Chlamydomonas sp. [85]. Upregulated citrate may provide acetyl-CoA in cytoplasm which can further be utilized to produce FA molecules. Citric acid was highly upregulated in both N- and P- cells. Similarly, 2-ketoglutaric acid has also emerged as a master regulator in essential pathways. Like citric acid, it is also a cataplerotic molecule, enhancing to provide synthesis and regulation of other molecules desired by the cells. It was found to be interacting with the regulator of acetyl-CoA carboxylase enzyme (ACCase), thus relieving ACCase for fatty acid biosynthesis [49]. 2-Ketoglutaric acid was also found to increase in nitrogen stress, providing backbone for nitrogen assimilation [97]. Amino acid degradation may also lead to accumulation of 2-ketoglutarate, which can be further converted back to citrate for FA synthesis [98].

Trehalose was found to be upregulated in nitrogenand sulphur-deprived cells. Trehalose is a non-reducing disaccharide that performs a variety of functions, from carbon storage to carbon metabolism, protection from osmotic stress, stabilization of membranes and proteins, removal of aberrant storage material, protection from oxygen radicals, induction of autophagy [36, 85, 99]. The induction of trehalose might be responsible for growth retardation in N- and S- conditions. Previous reports also observed an increase in trehalose under nitrogen starvation in Chlamydomonas after 6 days of depletion [85]. Trehalose may also control various metabolic processes and growth [100]. It may act as a growth regulator by affecting hexokinase and thus glycolysis, and leads to severe growth defects such as dwarfism in 
plants [101, 102]. Although sulphur deprivation does not show growth inhibition initially, later growth shunts probably because of increase in trehalose accumulation. This seems interesting as the presence of citric acid and 2-ketoglutaric acid in nitrogen and phosphorous starvation might induce lipid accumulation, while trehalose presence in nitrogen and sulphur depletion might result in growth retardation (Fig. 6). As a result, a crosstalk between these metabolites such as citric acid, 2-ketoglutaric acid and trehalose might be important for the production of biomass as well as lipid accumulation in marine microalgae $P$. kessleri.

\section{Conclusions}

Parachlorella kessleri subjected to nutrient deprivation shows growth retardation except under P- limitation. Nitrogen and phosphorous limitation played a major role in lipid accumulation. The qualitative metabolomics showed a variable shift in the metabolite flux in response to different stress conditions. A crosstalk between metabolites, namely citric acid, 2-ketoglutaric acid and trehalose, can be hypothesized to have greater impact on the production of biomass and lipid accumulation. To our knowledge, this report in the marine microalgae $P$. kessleri is a new paradigm to elucidate the molecular changes in the basis of metabolite redistribution subjected to nutrient-limiting conditions leading to insights on the production of biomass, biofuels and bioproducts $\left(\mathrm{B}^{3}\right)$ in non-model systems. In conclusion, marine strain Parachlorella kessleri with high biomass and higher lipid productivity was analysed where shuffling of certain metabolites when subjected to stress will dictate the profile changes that may prove to be a benchmark for over-expression of lipids without compromising growth. Further characterization of this strain may be a critical step towards making algae-derived biofuels economically competitive for industrial production.

\section{Methods \\ Microalgae and culture conditions}

Marine microalgae P. kessleri (I) (procured from Indian Institute of Technology-Madras, Chennai) was grown in minimal media $\mathrm{F} / 2$ [103] under constant illumination $\left(\sim 100 \mu \mathrm{mol} \mathrm{m} \mathrm{m}^{-2} \mathrm{~s}^{-1}\right.$ photosynthetically active radiation [PAR]) on an orbital shaker at $150 \mathrm{RPM}$ at $25^{\circ} \mathrm{C}$. The composition of media components for $\mathrm{F} / 2$ media $\left(\mathrm{g} \mathrm{L}^{-1}\right.$ ) is as follows- $\mathrm{NaNO}_{3}-0.075 ; \quad \mathrm{NaH}_{2} \mathrm{PO}_{4} \cdot 2 \mathrm{H}_{2} \mathrm{O}-0.005$; $\mathrm{Na}_{2} \mathrm{SiO}_{3} \cdot 9 \mathrm{H}_{2} \mathrm{O}-0.03$ in artificial sea water (ASW) prepared using $\mathrm{NaCl}-24 ; \quad \mathrm{MgCl}_{2} \cdot 6 \mathrm{H}_{2} \mathrm{O}-11$; $\mathrm{Na}_{2} \mathrm{SO}_{4}-4 ; \quad \mathrm{CaCl}_{2} \cdot 6 \mathrm{H}_{2} \mathrm{O}-2 ; \quad \mathrm{KBr}-0.1 ; \quad \mathrm{H}_{3} \mathrm{BO}_{3}-0.03$; $\mathrm{Na}_{2} \mathrm{SiO}_{3} \cdot 9 \mathrm{H}_{2} \mathrm{O}-0.005 ; \quad \mathrm{SrCl} \cdot 6 \mathrm{H}_{2} 0-0.04 ; \quad \mathrm{NaF}-0.003$;
$\mathrm{NH}_{4} \mathrm{NO}_{3}-0.002 ; \mathrm{Fe}_{3} \mathrm{PO}_{4} \cdot 4 \mathrm{H}_{2} \mathrm{O}-0.001$; trace metals solution (in $\mathrm{g} \mathrm{L}^{-1}$ ) $-1 \mathrm{~mL} \mathrm{~L}^{-1}\left[\mathrm{ZnSO}_{4} \cdot 7 \mathrm{H}_{2} \mathrm{O}-0.023 ; \mathrm{MnSO}_{4}\right.$. $\mathrm{H}_{2} \mathrm{O}-0.152 ; \mathrm{Na}_{2} \mathrm{MoO}_{4} \cdot 2 \mathrm{H}_{2} \mathrm{O}-0.007 ; \mathrm{CoSO}_{4} \cdot 7 \mathrm{H}_{2} \mathrm{O}-0.014$; $\mathrm{CuCl}_{2} \cdot 2 \mathrm{H}_{2} \mathrm{O}-0.007 ; \quad \mathrm{Fe}\left(\mathrm{NH}_{4}\right) 2\left(\mathrm{SO}_{4}\right)_{2} \cdot 6 \mathrm{H}_{2} \mathrm{O}-4.6$; $\mathrm{Na}_{2}$ EDTA $\left.2 \mathrm{H}_{2} \mathrm{O}-4.4\right]$; and vitamin $\mathrm{B}_{12}{ }^{*}-0.135 \mathrm{mg} \mathrm{L}{ }^{-1}$; biotin vitamin solution*- $-0.025 \mathrm{mg} \mathrm{L}^{-1}$; thiamine vitamin solution*- $0.335 \mathrm{mg} \mathrm{L}^{-1}$ ("added after autoclaving the media). Growth and biomass accumulation were monitored by cell count using haemocytometer [104] and dry weight (dw) analysis as described previously [105]. Growth rates were obtained using the following equation [106]

$$
K=\frac{\ln \frac{N_{2}}{N_{1}}}{t_{2}-t_{1}}
$$

where $N_{1}$ and $N_{2}$ represent cell counts at initial time $\left(t_{1}\right)$ and final time $\left(t_{2}\right)$, respectively. Doubling time was calculated depending on the specific growth rate [107].

$$
\text { Doubling time }=\frac{\ln 2}{K} .
$$

Cells were initially grown photoautotrophically to the middle of the logarithmic phase in F/2 medium. These cells were collected by centrifugation and resuspended again at a density of $2 \times 10^{6}$ cells mL $\mathrm{mL}^{-1}$ in regular $\mathrm{F} / 2$ or in the same media completely deficit in nitrogen $(\mathrm{N}-)$, phosphorous (P-) or sulphur (S-). Nitrogen concentration in the media was estimated during culture growth spectrophotometrically as described by Yodsuwan et al. [108]. Samples for all the analyses were taken immediately after resuspension (control, 0 day) and at the time intervals of 2, 4, 6, 8 and 10 days for further experiments, and the sixth-day samples were analysed for metabolomic profiling.

\section{Biochemical analysis}

The samples were analysed for changes in the biochemical constituents [pigments (total chlorophyll), proteins, carbohydrates] subjected to the nutrient stress. For estimation of pigments, $1 \mathrm{~mL}$ of culture was pellet down and resuspended in $1 \mathrm{~mL}$ of absolute methanol. The suspension was vortexed briefly and incubated at $4{ }^{\circ} \mathrm{C}$ for an hour to extract the pigments completely. The debris was pellet down, and the suspension was used to measure absorbance at 665,652 and $470 \mathrm{~nm}$ to calculate total chlorophyll content [109]. Protein estimation was done using modified biuret method. Total soluble proteins were extracted using $1 \mathrm{~N} \mathrm{NaOH}$ in $25 \%$ methanol as extraction buffer. 1-2 $\mathrm{mL}$ of culture was pellet down and resuspended in $1 \mathrm{~mL}$ of extraction buffer and incubated at $80{ }^{\circ} \mathrm{C}$ for $15 \mathrm{~min}$. The sample was cooled down to room temperature and centrifuged at high speed to remove debris. One hundred microlitres of extract was 
mixed with $50 \mu \mathrm{L}$ of $\mathrm{CuSO}_{4}$ solution $\left(0.21 \% \mathrm{CuSO}_{4}\right.$ in $30 \% \mathrm{NaOH}$ ), incubated at RT for $10 \mathrm{~min}$ and its absorbance was measured at $310 \mathrm{~nm}$ [110]. Carbohydrate estimation was done using modified phenol-sulphuric acid method. Around $100 \mu \mathrm{L}$ of cells was taken, and absolute $\mathrm{H}_{2} \mathrm{SO}_{4}$ was added and kept for $1 \mathrm{~h}$ at room temperature. Afterwards, $5 \%$ phenol was added along with $1 \mathrm{~mL}$ of $\mathrm{H}_{2} \mathrm{SO}_{4}$ and kept at room temperature for another $20 \mathrm{~min}$ after vortexing. Absorbance was measured at $490 \mathrm{~nm}$ [111].

\section{Lipid quantification and profiling}

Total lipids were extracted using modified Bligh and Dyer procedure [112], dried under $\mathrm{N}_{2}$, and visualized as TAGs by thin-layer chromatography (TLC) on a silica gel plate. Briefly, $\sim 1 \times 10^{8}$ cells were collected in a glass tube with Teflon-lined screw cap. Lipid extraction was done using methanol/chloroform $(2: 1, \mathrm{v} / \mathrm{v})$ containing $0.01 \%$ butylated hydroxytoluene. Two millilitres of methanol/chloroform mix was added to the cell pellet and incubated at $25^{\circ} \mathrm{C}$ for $2 \mathrm{~h}$ with shaking. Thereafter, chloroform $(1 \mathrm{~mL})$ and water $(1.8 \mathrm{~mL})$ were added to the tubes, mixed vigorously, and centrifuged at $3000 \times g$ to separate the mix into two phases. The lower organic phase containing the extracted lipids was transferred to a new glass tube with the help of a Pasteur pipette. Extracted organic phase was dried at $50{ }^{\circ} \mathrm{C}$ under stream of nitrogen $\left(\mathrm{N}_{2}\right)$ to evaporate the solvent completely and resuspended in $\mathrm{CHCl}_{3} /$ $\mathrm{MeOH}(100 \mu \mathrm{L}, 6: 1 \mathrm{v} / \mathrm{v})$. Fifty microlitres of this extract was applied to a silica 60 thin-layer chromatography plate (Sigma-Aldrich) and run with a solvent system of heptane/ethanol/acetone $(70: 30: 1, \mathrm{v} / \mathrm{v} / \mathrm{v})$ to resolve the neutral lipids. The TAG band was identified by staining co-migrated TAG standard with iodine vapours [84]. For GC-MS analysis, $\sim 1 \times 10^{8}$ cells were acid-hydrolysed and methyl-esterified using $2 \%$ sulphuric acid in methanol $(300 \mu \mathrm{L})$ for $2 \mathrm{~h}$ at $80{ }^{\circ} \mathrm{C}$. Prior to the reaction, $50 \mu \mathrm{g}$ of heptadecanoic acid (Alfa Aesar) was added as internal standard. The fatty acid methyl esters were extracted using $300 \mu \mathrm{L}$ of $0.9 \%(\mathrm{w} / \mathrm{v}) \mathrm{NaCl}$ solution and $300 \mu \mathrm{L}$ of hexane. The mixture was vortexed briefly and centrifuged at $3000 \times g$ for $3 \mathrm{~min}$ to separate the phases. One microlitre of hexane layer was injected into a 7890A gas chromatography (GC) mass spectrometry (MS) system equipped with a $7000 \mathrm{GC} / \mathrm{MS}$ triple quadrupole system (Agilent) $[107,113]$. The running conditions for GC-MS were described by Agilent's RTL DBWax method [114].

\section{Qualitative metabolomics}

For the extraction of cellular metabolites, $\sim 10^{9}$ cells were collected by centrifugation at $8000 \times g$ for $10 \mathrm{~min}$ and immediately quenched in liquid nitrogen.
Metabolites were extracted using methanol, chloroform and water by repeated freezing and thawing. Cells were resuspended in $1 \mathrm{~mL}$ of ice-cold methanol/ chloroform/water (10:3:1) and vortexed briefly. The cells were frozen again in liquid nitrogen for 1-2 min and thawed on ice for 4-5 min. Freezing and thawing cycles were repeated five times with intermittent vortexing. Samples were then centrifuged at $14,000 \times g$ for $3 \mathrm{~min}$ at $4{ }^{\circ} \mathrm{C}$ to get rid of cell debris. The supernatant was filtered using a $0.2-\mu \mathrm{m}$ filter. One hundred microlitres of supernatant was taken and vacuum-dried at $4{ }^{\circ} \mathrm{C}$. The dried leftover was dissolved in $10 \mu \mathrm{L}$ of freshly prepared methoxyamine hydrochloride solution (40 mg mL $\mathrm{mL}^{-1}$ in pyridine) and incubated at $30{ }^{\circ} \mathrm{C}$ for 90 min with shaking. To the above solution, $90 \mu \mathrm{L}$ of $\mathrm{N}$-methyl- $\mathrm{N}$-(trimethylsilyl)trifluoroacetamide was added and incubated at $37{ }^{\circ} \mathrm{C}$ for $30 \mathrm{~min}$. The samples were centrifuged at $14,000 \times g$ for $3 \mathrm{~min}$, and the supernatant was taken for the GC/MS analysis. The samples were run on GC-MS/MS, and the data were analysed using MetaboAnalyst 4.0 (http://www.metab oanalyst.ca) [115].

\section{Statistical analysis}

All the experiments were done in biological triplicates, and the mean of three values was used to calculate standard deviation (SD). The final data were represented as mean \pm SD (denoting SD as the experimental error). Graphs were plotted using MS Excel software (Microsoft Corporation, USA).

\section{Abbreviations}

$\mathrm{N}$-: nitrogen deprivation; P-: phosphorous deprivation; S-: sulphur deprivation; TAGs: triacylglycerols; siROS: specific intracellular reactive oxygen species; PAR: photosynthetically active radiation; RPM: rotation per minute; TLC: thin-layer chromatography; FA: fatty acid; FAMEs: fatty acid methyl esters; SFAs: saturated fatty acid; PUFAs: polyunsaturated fatty acid; MUFAs: monounsaturated fatty acid; TCA: tricarboxylic acid; NAD(P)H: nicotinamide adenine dinucleotide phosphate; $C 4$ : Hatch-Slack pathway of $\mathrm{CO}_{2}$ fixation; ACCase: acetyl coenzyme A carboxylase; ATP: adenosine triphosphate; ADP: adenosine diphosphate; NOx: nitrogen oxides.

\section{Acknowledgements}

We would like to thank Mr. Shrikumar Suryanaran (Indian Institute of Technology, Madras) for providing us the strain.

\section{Authors' contributions}

KMS, AAN and PPJ designed the experiment. KMS and AAN executed the experiments. MZA and PPJ supervised the project. KMS wrote the manuscript with all the input from the authors. All authors read and approved the final manuscript.

\section{Funding}

The research was funded by the grants from the Department of Biotechnology, Government of India, to PPJ (Sanction No. BT/PB/Center/03/2011) and to AAN (BioCARe Scheme No. BT/PR18491/BIC/101/759/2016). Senior Research Fellowship to KMS from University Grants Commission (UGC), Government of India, is duly acknowledged. 


\section{Availability of data and materials}

All data generated or analysed during this study have been provided in this manuscript.

\section{Ethics approval and consent to participate}

Not applicable.

\section{Consent for publication}

All authors have given their consent for the publication of this work.

\section{Competing interests}

The authors declare that they have no competing interests.

\section{Author details}

${ }^{1}$ Omics of Algae Group, Integrative Biology, International Centre for Genetic Engineering and Biotechnology, Aruna Asaf Ali Marg, New Delhi 110067, India.

${ }^{2}$ Department of Biotechnology, School of Chemical and Life Sciences, Jamia Hamdard University, New Delhi 110062, India.

Received: 12 February 2019 Accepted: 5 July 2019

Published online: 15 July 2019

\section{References}

1. Scranton MA, Ostrand JT, Fields FJ, Mayfield SP. Chlamydomonas as a model for biofuels and bio-products production. Plant J. 2015;82(3):523-31.

2. Mata TM, Martins AA, Caetano NS. Microalgae for biodiesel production and other applications: a review. Renew Sustain Energy Rev. 2010;14(1):217-32.

3. Chisti Y. Biodiesel from microalgae. Biotechnol Adv. 2007;25(3):294-306.

4. Amaro HM, Guedes AC, Malcata FX. Advances and perspectives in using microalgae to produce biodiesel. Appl Energy. 2011;88(10):3402-10.

5. Abdelaziz AE, Leite GB, Hallenbeck PC. Addressing the challenges for sustainable production of algal biofuels: I. Algal strains and nutrient supply. Environ Technol. 2013;34(13-16):1783-805.

6. Abdelaziz AE, Leite GB, Hallenbeck PC. Addressing the challenges for sustainable production of algal biofuels: II. Harvesting and conversion to biofuels. Environ Technol. 2013;34(13-16):1807-36.

7. Leite GB, Abdelaziz AE, Hallenbeck PC. Algal biofuels: challenges and opportunities. Bioresour Technol. 2013:145:134-41.

8. Ono E, Cuello JL. Carbon dioxide mitigation using thermophilic cyanobacteria. Biosyst Eng. 2007:96(1):129-34.

9. Packer M. Algal capture of carbon dioxide; biomass generation as a tool for greenhouse gas mitigation with reference to New Zealand energy strategy and policy. Energy Policy. 2009;37(9):3428-37.

10. Markou G, Georgakakis D. Cultivation of filamentous cyanobacteria (blue-green algae) in agro-industrial wastes and wastewaters: a review. Appl Energy. 2011;88(10):3389-401.

11. Rawat I, Ranjith Kumar R, Mutanda T, Bux F. Dual role of microalgae: phycoremediation of domestic wastewater and biomass production for sustainable biofuels production. Appl Energy. 2011;88(10):3411-24.

12. Spolaore $P$, Joannis-Cassan C, Duran E, Isambert A. Commercial applications of microalgae. J Biosci Bioeng. 2006;101(2):87-96.

13. Raja R, Hemaiswarya S, Kumar NA, Sridhar S, Rengasamy R. A perspective on the biotechnological potential of microalgae. Crit Rev Microbiol. 2008;34(2):77-88.

14. Fang S-C. Metabolic engineering and molecular biotechnology of microalgae for fuel production. In: Pandey A, Lee D-J, Chisti Y, Soccol CR, editors. Biofuels from algae. Amsterdam: Elsevier; 2014. p. 47-65.

15. $\mathrm{Xu} \mathrm{H}, \mathrm{Miao} X, \mathrm{Wu} \mathrm{Q}$. High quality biodiesel production from a microalga Chlorella protothecoides by heterotrophic growth in fermenters. J Biotechnol. 2006;126(4):499-507.

16. Menon KR, Balan R, Suraishkumar GK. Stress induced lipid production in Chlorella vulgaris: relationship with specific intracellular reactive species levels. Biotechnol Bioeng. 2013;110(6):1627-36.

17. Abdelaziz AE, Ghosh D, Hallenbeck PC. Characterization of growth and lipid production by Chlorella sp. PCH90, a microalga native to Quebec. Bioresour Technol. 2014:156:20-8.
18. Tsai CH, Warakanont J, Takeuchi T, Sears BB, Moellering ER, Benning C. The protein compromised hydrolysis of triacylglycerols 7 (CHT7) acts as a repressor of cellular quiescence in Chlamydomonas. Proc Natl Acad Sci USA. 2014;111(44):15833-8.

19. Harwood JL, Guschina IA. The versatility of algae and their lipid metabolism. Biochimie. 2009;91(6):679-84.

20. Greenwell HC, Laurens LM, Shields RJ, Lovitt RW, Flynn KJ. Placing microalgae on the biofuels priority list: a review of the technological challenges. J R Soc Interface. 2010;7(46):703-26.

21. Gong $Y$, Jiang M. Biodiesel production with microalgae as feedstock: from strains to biodiesel. Biotechnol Lett. 2011;33(7):1269-84.

22. Cheng D, He Q. Assessment of environmental stresses for enhanced microalgal biofuel production-an overview. Front Energy Res. 2014:2:26.

23. Singh A, Pant D, Olsen SI, Nigam PS. Key issues to consider in microalgae based biodiesel production. Energy Educ Sci Technol. 2012;29(1):687-700.

24. Li Y, Han D, Hu G, Dauvillee D, Sommerfeld M, Ball S, et al. Chlamydomonas starchless mutant defective in ADP-glucose pyrophosphorylase hyper-accumulates triacylglycerol. Metab Eng. 2010;12(4):387-91.

25. Lv JM, Cheng LH, Xu XH, Zhang L, Chen HL. Enhanced lipid production of Chlorella vulgaris by adjustment of cultivation conditions. Bioresour Technol. 2010;101(17):6797-804.

26. Zheng Y, Chi Z, Lucker B, Chen S. Two-stage heterotrophic and phototrophic culture strategy for algal biomass and lipid production. Bioresour Technol. 2012;103(1):484-8.

27. Halim R, Danquah MK, Webley PA. Extraction of oil from microalgae for biodiesel production: a review. Biotechnol Adv. 2012;30(3):709-32.

28. Hanotu J, Bandulasena HC, Zimmerman WB. Microflotation performance for algal separation. Biotechnol Bioeng. 2012;109(7):1663-73.

29. Demirbas A, Fatih Demirbas M. Importance of algae oil as a source of biodiesel. Energy Convers Manag. 2011;52(1):163-70.

30. Cao J, Yuan H, Li B, Yang J. Significance evaluation of the effects of environmental factors on the lipid accumulation of Chlorella minutissima UTEX 2341 under low-nutrition heterotrophic condition. Bioresour Technol. 2014;152:177-84

31. Talebi AF, Tohidfar M, Tabatabaei M, Bagheri A, Mohsenpor M, Mohtashami SK. Genetic manipulation, a feasible tool to enhance unique characteristic of Chlorella vulgaris as a feedstock for biodiesel production. Mol Biol Rep. 2013;40(7):4421-8.

32. Singh B, Guldhe A, Rawat I, Bux F. Towards a sustainable approach for development of biodiesel from plant and microalgae. Renew Sustain Energy Rev. 2014;29:216-45.

33. Hu Q, Sommerfeld M, Jarvis E, Ghirardi M, Posewitz M, Seibert M, et al. Microalgal triacylglycerols as feedstocks for biofuel production: perspectives and advances. Plant J. 2008;54(4):621-39.

34. Singh NK, Dhar DW. Microalgae as second generation biofuel: a review. Agron Sustain Dev. 2011;31(4):605-29.

35. Sharma KK, Schuhmann H, Schenk PM. High lipid induction in microalgae for biodiesel production. Energies. 2012;5(5):1532.

36. Hirth M, Liverani S, Mahlow S, Bouget FY, Pohnert G, Sasso S. Metabolic profiling identifies trehalose as an abundant and diurnally fluctuating metabolite in the microalga Ostreococcus tauri. Metabolomics. 2017;13(6):68.

37. Shaikh KM, Nesamma AA, Abdin MZ. Jutur PP. Evaluation of growth and lipid profiles in six different microalgal strains for biofuel production. In: Kumar S, Sani R, Yadav Y, editors. Conference proceedings of the second international conference on recent advances in bioenergy research Springer proceedings in energy. Singapore: Springer; 2018. p. 3-16.

38. Li X, Pribyl P, Bisova K, Kawano S, Cepak V, Zachleder V, et al. The microalga Parachlorella kessleri-a novel highly efficient lipid producer. Biotechnol Bioeng. 2013;110(1):97-107.

39. Ota S, Oshima K, Yamazaki T, Kim S, Yu Z, Yoshihara M, et al. Highly efficient lipid production in the green alga Parachlorella kessleri: draft genome and transcriptome endorsed by whole-cell 3D ultrastructure. Biotechnol Biofuels. 2016;9(1):13.

40. Ahmad I, Fatma Z, Yazdani SS, Kumar S. DNA barcode and lipid analysis of new marine algae potential for biofuel. Algal Res. 2013;2(1):10-5. 
41. Sunda WG, Price NM, Morel FMM. Trace metal ion buffers and their use in culture studies. In: Andersen RA, editor. Algal culturing techniques. Amsterdam: Elsevier; 2005. p. 35-63.

42. Minhas AK, Hodgson P, Barrow CJ, Adholeya A. A review on the assessment of stress conditions for simultaneous production of microalgal lipids and carotenoids. Front Microbiol. 2016;7:546.

43. Guarnieri MT, Nag A, Smolinski SL, Darzins A, Seibert M, Pienkos PT. Examination of triacylglycerol biosynthetic pathways via de novo transcriptomic and proteomic analyses in an unsequenced microalga. PLoS ONE. 2011;6(10):e25851.

44. Cakmak T, Angun P, Demiray YE, Ozkan AD, Elibol Z, Tekinay T. Differential effects of nitrogen and sulfur deprivation on growth and biodiesel feedstock production of Chlamydomonas reinhardtii. Biotechnol Bioeng 2012;109(8):1947-57.

45. Gao Y, Yang M, Wang C. Nutrient deprivation enhances lipid content in marine microalgae. Bioresour Technol. 2013;147:484-91.

46. Xiao Y, Zhang J, Cui J, Feng Y, Cui Q. Metabolic profiles of Nannochloropsis oceanica IMET1 under nitrogen-deficiency stress. Bioresour Technol. 2013;130:731-8

47. Lamers PP, Janssen M, De Vos RC, Bino RJ, Wijffels RH. Carotenoid and fatty acid metabolism in nitrogen-starved Dunaliella salina, a unicellular green microalga. J Biotechnol. 2012;162(1):21-7.

48. Breuer G, Lamers PP, Martens DE, Draaisma RB, Wijffels RH. The impact of nitrogen starvation on the dynamics of triacylglycerol accumulation in nine microalgae strains. Bioresour Technol. 2012;124:217-26.

49. Huergo LF, Dixon R. The emergence of 2-oxoglutarate as a master regulator metabolite. Microbiol Mol Biol Rev. 2015;79(4):419-35.

50. Gordon JM, Polle JE. Ultrahigh bioproductivity from algae. Appl Microbiol Biotechnol. 2007;76(5):969-75

51. Lim DKY, Schenk PM, Schuhmann H. Perspectives on metabolic engineering for increased lipid contents in microalgae. Biofuels. 2012;3(1):71-86

52. Valenzuela J, Mazurie A, Carlson RP, Gerlach R, Cooksey KE, Peyton $\mathrm{BM}$, et al. Potential role of multiple carbon fixation pathways during lipid accumulation in Phaeodactylum tricornutum. Biotechnol Biofuels. 2012;5(1):40.

53. Boussiba S, Vonshak A, Cohen Z, Avissar Y, Richmond A. Lipid and biomass production by the halotolerant microalga Nannochloropsis salina. Biomass. 1987;12(1):37-47.

54. Roessler PG. Environmental control of glycerolipid metabolism in microalgae: commercial implications and future research directions. J Phycol. 1990;26(3):393-9.

55. Thompson GA Jr. Lipids and membrane function in green algae. Biochim Biophys Acta. 1996;1302(1):17-45.

56. Khozin-Goldberg I, Bigogno C, Shrestha P, Cohen Z. Nitrogen starvation induces the accumulation of arachidonic acid in the freshwater green alga Parietochloris Incisa (Trebuxiophyceae). J Phycol. 2002;38(5):991-4.

57. Zhekisheva M, Boussiba S, Khozin-Goldberg I, Zarka A, Cohen Z. Accumulation of oleic acid in Haematococcus pluvialis (Chlorophyceae) under nitrogen starvation or high light is correlated with that of astaxanthin esters. J Phycol. 2002:38(2):325-31.

58. Guschina IA, Harwood JL. Lipids and lipid metabolism in eukaryotic algae. Prog Lipid Res. 2006:45(2):160-86.

59. Solovchenko AE, Khozin-Goldberg I, Didi-Cohen S, Cohen Z, Merzlyak MN. Effects of light and nitrogen starvation on the content and composition of carotenoids of the green microalga Parietoch/oris incisa. Russ J Plant Physiol. 2008;55(4):455-62.

60. Pal D, Khozin-Goldberg I, Cohen Z, Boussiba S. The effect of light, salinity, and nitrogen availability on lipid production by Nannochloropsis sp. Appl Microbiol Biotechnol. 2011;90(4):1429-41.

61. Khozin-Goldberg I, Shrestha P, Cohen Z. Mobilization of arachidonyl moieties from triacylglycerols into chloroplastic lipids following recovery from nitrogen starvation of the microalga Parietochloris incisa. Biochim Biophys Acta. 2005;1738(1-3):63-71.

62. Fields MW, Hise A, Lohman EJ, Bell T, Gardner RD, Corredor L, et al. Sources and resources: importance of nutrients, resource allocation, and ecology in microalgal cultivation for lipid accumulation. Appl Microbiol Biotechnol. 2014:98(11):4805-16.

63. Iwai M, Hori K, Sasaki-Sekimoto Y, Shimojima M, Ohta H. Manipulation of oil synthesis in Nannochloropsis strain NIES-2145 with a phosphorus starvation-inducible promoter from Chlamydomonas reinhardtii. Front Microbiol. 2015;6:912.

64. Guo J, Wilken S, Jimenez V, Choi CJ, Ansong C, Dannebaum R, et al. Specialized proteomic responses and an ancient photoprotection mechanism sustain marine green algal growth during phosphate limitation. Nat Microbiol. 2018;3(7):781-90.

65. Ballin G, Doucha J, Zachleder V, Šetll'k I. Macromolecular syntheses and the course of cell cycle events in the chlorococcal alga Scenedesmus quadricauda under nutrient starvation: effect of nitrogen starvation. Biol Plant. 1988;30(2):81-91.

66. Šetlík I, Ballin G, Doucha J, Zachleder V. Macromolecular syntheses and the course of cell cycle events in the chlorococcal alga Scenedesmus quadricauda under nutrient starvation: effect of sulphur starvation. Biol Plant. 1988:30(3):161-9.

67. Zachleder V, Ballin G, Doucha J, Šetlík I. Macromolecular syntheses and the course of cell cycle events in the chlorococcal alga Scenedesmus quadricauda under nutrient starvation: effect of phosphorus starvation. Biol Plant. 1988;30(2):92-9.

68. Branyikova I, Marsalkova B, Doucha J, Branyik T, Bisova K, Zachleder V, et al. Microalgae-novel highly efficient starch producers. Biotechnol Bioeng. 2011;108(4):766-76

69. Yao C, Ai J, Cao X, Xue S, Zhang W. Enhancing starch production of a marine green microalga Tetraselmis subcordiformis through nutrient limitation. Bioresour Technol. 2012;118:438-44.

70. Halsey KH, O'Malley RT, Graff JR, Milligan AJ, Behrenfeld MJ. A common partitioning strategy for photosynthetic products in evolutionarily distinct phytoplankton species. New Phytol. 2013;198(4):1030-8.

71. Ito T, Tanaka M, Shinkawa H, Nakada T, Ano Y, Kurano N, et al. Metabolic and morphological changes of an oil accumulating trebouxiophycean alga in nitrogen-deficient conditions. Metabolomics. 2013;9(Suppl 1):178-87.

72. Courchesne NM, Parisien A, Wang B, Lan CQ. Enhancement of lipid production using biochemical, genetic and transcription factor engineering approaches. J Biotechnol. 2009;141(1-2):31-41.

73. Radakovits R, Jinkerson RE, Darzins A, Posewitz MC. Genetic engineering of algae for enhanced biofuel production. Eukaryot Cell. 2010;9(4):486-501.

74. Li Y, Horsman M, Wang B, Wu N, Lan CQ. Effects of nitrogen sources on cell growth and lipid accumulation of green alga Neochloris oleoabundans. Appl Microbiol Biotechnol. 2008;81(4):629-36.

75. Rodolfi L, Chini Zittelli G, Bassi N, Padovani G, Biondi N, Bonini G, et al. Microalgae for oil: strain selection, induction of lipid synthesis and outdoor mass cultivation in a low-cost photobioreactor. Biotechnol Bioeng. 2009;102(1):100-12.

76. Alvarez-Diaz PD, Ruiz J, Arbib Z, Barragan J, Garrido-Perez C, Perales JA. Lipid production of microalga Ankistrodesmus falcatus increased by nutrient and light starvation in a two-stage cultivation process. Appl Biochem Biotechnol. 2014;174(4):1471-83.

77. Feng P, Deng Z, Fan L, Hu Z. Lipid accumulation and growth characteristics of Chlorella zofingiensis under different nitrate and phosphate concentrations. J Biosci Bioeng. 2012;114(4):405-10.

78. Zhu LD, Li ZH, Hiltunen E. Strategies for lipid production improvement in microalgae as a biodiesel feedstock. Biomed Res Int. 2016;2016:8792548.

79. Xin L, Hu HY, Ke G, Sun YX. Effects of different nitrogen and phosphorus concentrations on the growth, nutrient uptake, and lipid accumula tion of a freshwater microalga Scenedesmus sp. Bioresour Technol. 2010;101(14):5494-500.

80. Chu FF, Chu PN, Shen XF, Lam PK, Zeng RJ. Effect of phosphorus on biodiesel production from Scenedesmus obliquus under nitrogendeficiency stress. Bioresour Technol. 2014;152:241-6.

81. Benjumea P, Agudelo JR, Agudelo AF. Effect of the degree of unsaturation of biodiesel fuels on engine performance, combustion characteristics, and emissions. Energy Fuels. 2011;25(1):77-85.

82. Wang ZT, Ullrich N, Joo S, Waffenschmidt S, Goodenough U. Algal lipid bodies: stress induction, purification, and biochemical characterization in wild-type and starchless Chlamydomonas reinhardtii. Eukaryot Cell. 2009:8(12):1856-68.

83. Takahashi H, Braby CE, Grossman AR. Sulfur economy and cell wall biosynthesis during sulfur limitation of Chlamydomonas reinhardtii. Plant Physiol. 2001;127(2):665-73. 
84. Msanne J, Xu D, Konda AR, Casas-Mollano JA, Awada T, Cahoon EB, et al Metabolic and gene expression changes triggered by nitrogen deprivation in the photoautotrophically grown microalgae Chlamydomonas reinhardtii and Coccomyxa sp. C-169. Phytochemistry. 2012;75:50-9.

85. Wase N, Black PN, Stanley BA, DiRusso CC. Integrated quantitative analysis of nitrogen stress response in Chlamydomonas reinhardtii using metabolite and protein profiling. J Proteome Res. 2014;13(3):1373-96.

86. Fiehn O. Metabolomics by gas chromatography-mass spectrometry: combined targeted and untargeted profiling. Curr Protoc Mol Biol. 2016;114:30.4.1-4.32.

87. Martel CM. Nitrogen-deficient microalgae are rich in cell-surface mannose: potential implications for prey biorecognition by phagotrophic protozoa. Braz J Microbiol. 2009;40:86-9.

88. Lim M-H, Lee O-H, Chin J-E, Ko H-M, Kim I-C, Lee HB, et al. Simultaneous degradation of phytic acid and starch by an industrial strain of Saccharomyces cerevisiae producing phytase and a-amylase. Biotechnol Lett. 2008;30(12):2125-30.

89. Zhang Y, Adams IP, Ratledge C. Malic enzyme: the controlling activity for lipid production? Overexpression of malic enzyme in Mucor circinelloides leads to a 2.5-fold increase in lipid accumulation. Microbiology. 2007;153(Pt 7):2013-25.

90. Roberts K, Granum E, Leegood RC, Raven JA. C3 and C4 pathways of photosynthetic carbon assimilation in marine diatoms are under genetic, not environmental, control. Plant Physiol. 2007;145(1):230-5.

91. Xu J, Fan X, Zhang X, Xu D, Mou S, Cao S, et al. Evidence of coexistence of C(3) and C(4) photosynthetic pathways in a green-tide-forming alga, Ulva prolifera. PLoS ONE. 2012;7(5):e37438.

92. Fritsche $S$, Wang $X$, Jung $C$. Recent advances in our understanding of tocopherol biosynthesis in plants: an overview of key genes, functions, and breeding of vitamin E improved crops. Antioxidants (Basel). 2017:6(4):99.

93. Sakuragi Y, Maeda H, Dellapenna D, Bryant DA. alpha-Tocopherol plays a role in photosynthesis and macronutrient homeostasis of the cyanobacterium Synechocystis sp. PCC 6803 that is independent of its antioxidant function. Plant Physiol. 2006;141(2):508-21.

94. Muhlroth A, Li K, Rokke G, Winge P, Olsen Y, Hohmann-Marriott MF, et al. Pathways of lipid metabolism in marine algae, co-expression network, bottlenecks and candidate genes for enhanced production of EPA and DHA in species of Chromista. Mar Drugs. 2013;11(11):4662-97.

95. Ratledget C, Evans CT. The physiological significance of citric acid in the control of metabolism in lipid-accumulating yeasts. Biotechnol Genet Eng Rev. 1985:3(1):349-76.

96. Bellou S, Aggelis G. Biochemical activities in Chlorella sp. and Nannochloropsis salina during lipid and sugar synthesis in a lab-scale open pond simulating reactor. J Biotechnol. 2012;164(2):318-29.

97. Chen H, Zheng Y, Zhan J, He C, Wang Q. Comparative metabolic profiling of the lipid-producing green microalga Chlorella reveals that nitrogen and carbon metabolic pathways contribute to lipid metabolism. Biotechnol Biofuels. 2017:10:153.

98. Yang C, Ko B, Hensley CT, Jiang L, Wasti AT, Kim J, et al. Glutamine oxidation maintains the TCA cycle and cell survival during impaired mitochondrial pyruvate transport. Mol Cell. 2014;56(3):414-24.

99. Jain NK, Roy I. Effect of trehalose on protein structure. Protein Sci. 2009;18(1):24-36.

100. Elbein AD, Pan YT, Pastuszak I, Carroll D. New insights on trehalose: a multifunctional molecule. Glycobiology. 2003;13(4):17R-27R.
101. Müller J, Wiemken A, Aeschbacher R. Trehalose metabolism in sugar sensing and plant development. Plant Sci. 1999;147(1):37-47.

102. Vogel G, Aeschbacher RA, Muller J, Boller T, Wiemken A. Trehalose6-phosphate phosphatases from Arabidopsis thaliana: identification by functional complementation of the yeast tps 2 mutant. Plant J. 1998;13(5):673-83.

103. Guillard RR, Ryther JH. Studies of marine planktonic diatoms. I. Cyclotella nana Hustedt, and Detonula confervacea (cleve) Gran. Can J Microbiol. 1962:8:229-39.

104. Guillard RR, Sieracki MS. Counting cells in cultures with the light microscope. In: Andersen RA, editor. Algal culturing techniques. London: Elsevier Academic Press; 2005. p. 239-52.

105. Sluite A, Hames B, Ruiz R, Scarlata C, Sluiter J, Templeton D. Determination of total solids in biomass and total dissolved solids in liquid process samples: laboratory analytical procedure. Golden: National Renewable Energy Laboratory; 2008.

106. Levasseur M, Thompson PA, Harrison PJ. Physiological acclimation of marine phytoplankton to different nitrogen sources. J Phycol. 1993;29(5):587-95.

107. Duong VT, Thomas-Hall SR, Schenk PM. Growth and lipid accumulation of microalgae from fluctuating brackish and sea water locations in South East Queensland-Australia. Front Plant Sci. 2015;6:359.

108. Yodsuwan N, Sawayama S, Sirisansaneeyakul S. Effect of nitrogen concentration on growth, lipid production and fatty acid profiles of the marine diatom Phaeodactylum tricornutum. Agric Nat Resour. 2017;51(3):190-7.

109. Lichtenthaler HK, Wellburn AR. Determinations of total carotenoids and chlorophylls $\mathrm{a}$ and $\mathrm{b}$ of leaf extracts in different solvents. Biochem Soc Trans. 1983:11(5):591.

110. Chen Y, Vaidyanathan S. Simultaneous assay of pigments, carbohydrates, proteins and lipids in microalgae. Anal Chim Acta. 2013;776:31-40

111. Paliwal C, Pancha I, Ghosh T, Maurya R, Chokshi K, Vamsi Bharadwaj SV, et al. Selective carotenoid accumulation by varying nutrient media and salinity in Synechocystis sp. CCNM 2501. Bioresour Technol. 2015;197:363-8.

112. Bligh EG, Dyer WJ. A rapid method of total lipid extraction and purification. Can J Biochem Physiol. 1959;37(8):911-7.

113. Lim DK, Garg S, Timmins M, Zhang ES, Thomas-Hall SR, Schuhmann $\mathrm{H}$, et al. Isolation and evaluation of oil-producing microalgae from subtropical coastal and brackish waters. PLOS ONE. 2012;7(7):e40751.

114. Brown MR. The amino-acid and sugar composition of 16 species of microalgae used in mariculture. J Exp Mar Biol Ecol. 1991;145(1):79-99.

115. Chong J, Soufan O, Li C, Caraus I, Li S, Bourque G, et al. MetaboAnalyst 4.0: towards more transparent and integrative metabolomics analysis. Nucleic Acids Res. 2018;46(W1):W486-94.

\section{Publisher's Note}

Springer Nature remains neutral with regard to jurisdictional claims in published maps and institutional affiliations. 